\title{
PENGARUH PRODUCT ASSORTMENT DAN GAYA HIDUP HEDONIS TERHADAP IMPULSE BUYING PENGUNJUNG TRANS STUDIO MALL (TSM) BANDUNG
}

\author{
Bob Foster \\ (Universitas Informatika dan Bisnis Indonesia) \\ E-mail bobnet@indosat.net.id
}

\begin{abstract}
ABSTRAK Penelitian ini bertujuan untuk mengetahui pengaruh product assortment dan gaya hidup hedonis / hedonic lifestyle terhadap impulse buying. Terdapat tiga variable yang diteliti, yaitu product assortment, hedonic lifestyle dan impulse buying. Penelitian ini mengambil lokasi di Trans Studio Mall (TSM) Bandung dengan target populasi konsumen yang pernah berbelanja di Trans Studio Mall. Pengambilan sampel penelitian dengan metode judgmental sampling. Sampel minimal yang dibutuhkan adalah sebanyak 200 sampel. Teknik analisis menggunakan analisis regresi linear berganda. Temuan utama penelitian menunjukkan bahwa product assortment berpengaruh terhadap impulse buying di Trans Studio Mall. Demikian juga hedonic lifestyle berpengaruh signifikan terhadap impulse buying di Trans Studio Mall.
\end{abstract}

Kata kunci: hedonic lifestyle , product assortment, impulse buying

\section{IMFLUENCE OF PRODUCT ASSORTMENT AND HEDONIC LIFESTYLE ON IMPULSE BUYING CUSTOMER OF TRANS STUDIO MALL (TSM)}

Abstrack This study aims to determine the effect of product assortment and hedonic lifestyle of impulse buying. There are three variables studied, ie product assortment, hedonic lifestyle and impluse buying. The study was on location in Trans Studio Mall (TSM) Bandung target consumer population ever shop at Trans Studio Mall. Research sampling with judgmental sampling method. Is the minimum necessary sample of 200 samples. Technical analysis using multiple linear regression analysis. The main findings showed that the product assortment influence on impulse buying at Trans Studio Mall. Similarly, hedonic lifestyle significant effect on impulse buying at Trans Studio Mall.

Keyword : hedonic lifestyle, product assortment, impulse buying

\section{PENDAHULUAN}

Saat ini pusat perbelanjaan modern yang lebih dikenal dengan istilah Mall mengalami pergeseran fungsi, awalnya masyarakat mengunjungi mall dengan tujuan untuk berbelanja berbagai keperluan mereka, namun saat ini mall telah berubah fungsi bukan hanya tempat untuk berbelanja barang yang dibutuhkan, tetapi juga sekaligus sebagai tempat hiburan untuk keluarga dan semua segmen pengunjung yang memberikan suatu sarana yang menarik dan rekreatif. Menurut Dittmar, Beattie \& Friese dalam Herabadi, et al. (2009), berbelanja tidak hanya untuk mendapatkan keperluan akan barang-barang atau memenuhi kebutuhan, tetapi menjadi sebuah aktifitas lifestyle dan mungkin untuk memenuhi kebutuhan psikologi. Kategori baru dari sarana perdagangan modern di Indonesia terdiri dari pusat perbelanjaan (mall), departemen store, hypermarket, supermarket, minimarket, factory outlet, distribusi outlet, dan fast food. Selama tahun 2011 pasar modern masih didominasi oleh pertumbuhan minimarket dengan proporsi pasar sebesar $48 \%$. Diikuti dengan sarana perdagangan lain seperti factory outlet, distribusi outlet, dan fast food sebesar 41\%, mall 4\%, hypermarket $1 \%$, supermarket $4 \%$ dan departement store menguasai pasar $2 \%$.

Menurut data Aprindo tahun 2010 Kota Bandung adalah kota yang memiliki pusat perbelanjaan atau mall terbanyak ketiga di Indonesia, Salah satu mall yang ada di kota Bandung adalah Trans Studio Mall. Trans Studio Mall merupakan pusat perbelanjaan yang tidak hanya menjadi tempat berbelanja barangbarang kebutuhan saja, tetapi juga sebagai tempat hiburan keluarga. Kawasan Terpadu Trans Studio Bandung terletak di Bandung sebagai salah satu tujuan wisata yang paling banyak dikunjungi di Indonesia.. Berdasarkan sumber yang didapatkan dari manajemen Trans Studio Mall, pada tahun 2010 pengunjung Trans Studio Mall sebesar 7.465.000, pada tahun 2011 mengalami peningkatan pengunjung yaitu sebesar 7.840.000. Pada tahun 2012 pengunjung Trans Studio Mall kembali meningkat menjadi 8.260.000. Persaingan merupakan hal yang harus diperhatikan pusat perbelanjaan untuk terus bertahan terutama dikawasan kota Bandung. Salah satu yang harus diperhatikan adalah keragaman produk, Penyediaan keragaman produk (produk assortment) yang baik tidak hanya akan menarik minat tetapi dapat mempengaruhi keputusan konsumen untuk berbelanja. Hal ini memungkinkan mereka menjadi pelanggan yang setia dan pada akhirnya dapat mencapai sasaran dan tujuan perusahaan. Konsumen saat ini tidak hanya memperhatikan kebutuhan primer dan sekundernya saja tetapi mereka sekarang telah melihat kebutuhan tersier yg harus dipenuhi juga. Berkunjung ke mall bisa dikatakan telah menjadi sebuah gaya hidup, terutama gaya hidup yang menjurus kepada hedonisme, Hedonisme secara etimologi berasal dari kata tunggal bahasa Yunani yaitu Hedone, yang dapat diartikan sebagai nikmat atau kenikmatan. Hedonisme, muncul kira-kira 400 SM dengan madzhabnya yang bernama Tyrene. Sedangkan perintis dari faham hedonisme adalah 
Epicurus.Menurut Pospoprodijo (1999:60) Hedonisme adalah kesenangan atau (kenikmatan) adalah tujuan akhir hidup dan yang baik yang tertinggi. Namun, kaum hedonis memiliki kata kesenangan menjadi kebahagiaan.

Sedangkan pembelian itu sendiri dapat bersifat impulsif, Silvera et al. (2008) mengemukakan bahwa pembeli impulsif lebih memperhatikan pertimbangan hedonik dibandingkan pertimbangan utilitarian pada pembelian yang dilakukan, dan pengalaman berbelanja yang dirasakan cenderung didorong oleh emosi yang tinggi seperti kegembiraan dan kesenangan. Peritel seharusnya lebih berfokus pada emosi positif konsumen dan pengalaman hedonik dalam gerai karena dapat meningkatkan terjadinya pembelian impulsif (Park et al., 2006). Dari berbagai kajian tersebut di atas Penulis merumuskan impulse buying sebagai aspek yang dapat dipengaruhi gaya hidup hedonis dan product assortment. Berkembangnya pusat perbelanjaan modern di Bandung dan persaingannya yang sangat ketat mengharuskan Trans Studio Mall memiliki strategi yang efektif agar memiliki keunggulan kompetitif.Berdasarkan latar belakang tersebut maka penulis tertarik untuk melakukan penelitian mengenai pengaruh gaya hidup hedonis dan product assortment terhadap impulse buying konsumen. Penelitian dilakukan di salah satu mall yang berada di Bandung yaitu Trans Studio Mall. Oleh karena itu penulis mengambil judul "Pengaruh Product assortment dan Gaya hidup hedonis terhadap Impulse Buying di Trans Studio Mall".

Menurut ahli "impulse buying is a non deliberate action and is accompanied by strong emotional responses" (Rook \& Gardner dalam Herabadi, et al., 2009) yang memiliki arti bahwa impulse buying adalah tindakan tanpa sengaja dan diikuti oleh respon emosional yang kuat.

Sehingga dapat disimpulkan bahwa impulse buying adalah pembelian yang tidak direncanakan dan disertai oleh respon emosional yang tinggi. Impulse buying didorong oleh keinginan yang bersifat spontanitas dan emosional. Ketika melakukan pembelian, konsumen akan lebih banyak mengandalkan perasaan dan cenderung lebih dinilai irrational dibanding rational. Perilaku impulse buying dapat dipahami sebagai suatu perilaku pembelian yang sedikit melibatkan proses kognitif dan melibatkan proses efektif yang cukup tinggi. Pembelian impulsif nampaknya tidak merefleksikan pikiran dalam berbelanja dan tertarik secara emosional terhadap suatu objek untuk memenuhi kepuasan dengan segera.

Konsumen melakukan aktivitas berbelanja pada awalnya dimotivasi oleh motif yang bersifat rasional, yaitu berkenaan dengan manfaat yang diberikan oleh produk (nilai utilitarian). Tetapi saat ini konsumen dipengaruhi oleh nilai lain dalam berbelanja yaitu nilai yang bersifat emosional atau yang dikenal dengan nilai hedonik.

Dari pengertian diatas dapat disimpulkan bahwa hedonic lifestyle adalah dorongan berbelanja untuk mencari kesenangan yang berhubungan dengan aspek multi-sensori, fantasi, dan emosi sehingga tidak memperhatikan manfaat dari produk yang dibeli (Utami, 2010:47).

Dalam proses penyediaan produk yang ditawarkan untuk konsumen perusahaan harus memperhatikan bauran produk yang ada pada saat ini dan di masa yang akan datang. Kotler dan Keller(2007:15) mendefinisikan keragaman produk sebagai berikut:

"Keragaman produk adalah kumpulan seluruh produk dan barang yang ditawarkan penjual tertentu kepada pembeli".

Sedangkan menurut Henry Simamora(2000 ; 441) mendefinisikan keragaman produk sebagai berikut

"Keragaman produk (product assortment) ialah seperangkat lini produk dan unsur yang ditawarkan oleh penjual tertentu pada para pembeli".

Dari definisi di atas dapat diambil rumusan bahwa Keragaman produk (product assortment) adalah kumpulan seluruh lini produk dan unsur yang ditawarkan oleh penjual kepada pembeli, termasuk di dalamnya jumlah lini produk, pilihan ukuran produk, dan pilihan warna.

\section{METODE}

Objek penelitian merupakan sasaran untuk mendapatkan tujuan tertentu mengenai suatu hal yang dibuktikan secara objektif untuk mendapatkan data sesuai dengan tujuan dan kegunaan tertentu. Adapun objek penelitian yang penulis teliti adalah perilaku berbelanja konsumen yaitu perilaku pembelian impulsif yang dikaitkan dengan hedonic lifestyle dan product assortment. Lokasi penelitian ini adalah Trans Studio Mall yang terletak di Jalan Gatot Subroto Bandung. Alasan penulis menggunakan Trans Studio Mall adalah karena Trans Studio Mall ini merupakan salah satu mall terbesar dan berkembang pesat di Bandung.

Dalam pemecahan masalah yang ada suatu penelitian diperlukan penyelidikan yang hatihati, teratur dan terus-menerus, sedangkan untuk mengetahui bagaimana seharusnya langkah penelitian harus dilakukan dengan menggunakan metode penelitian. Berdasarkan rumusan tujuan sebelumnya, metode penelitian yang digunakan penulis dalam menyusun penelitian ini menggunakan metode deskriptif yang bertujuan untuk mendapatkan bukti sebab akibat antara variabel-variabel penelitian yang terdiri atas product assortment, hedonic lifestyle , dan impulse buying.

Untuk memperoleh data dan informasi dalam penelitian ini, maka dilakukan pengungkapan sejumlah variable yang akan dioperasionalisasikan yang merupakan unsur-unsur yang terkandung di dalam hipotesis penelitian yang telah dirumuskan sebelumnya melalui penjelasan yang konkret dari setiap variable yang ada, sehingga indikatornya dapat ditetapkan berdasarkan penjelasan tersebut. Di dalam penelitian ini operasional variabel yang digunakan adalah hedonic lifestyle dan product assortment sebagai variabel independent (X), dan impulse buying bertindak sebagai variabel dependen $(\mathrm{Y})$. dimana indikator - indikatornya sebagai berikut : 
Tabel 1. Operasionalisasi Variabel

\begin{tabular}{|c|c|c|}
\hline No & Variable & Indicator \\
\hline \multirow{4}{*}{1} & \multirow{4}{*}{ product assortment } & $\begin{array}{l}\text { kesan bangunan atau } \\
\text { gedung } \\
\text { kerapihan dan } \\
\text { kebersihan ruangan } \\
\text { pencahayaan }\end{array}$ \\
\hline & & Musik \\
\hline & & Display yg menarik \\
\hline & & $\begin{array}{l}\text { Keleluasaan gang di } \\
\text { Mall } \\
\text { Kenikmatan }\end{array}$ \\
\hline \multirow{4}{*}{2} & \multirow{4}{*}{ hedonic lifestyle } & Kesenangan \\
\hline & & Keingintahuan \\
\hline & & Hiburan \\
\hline & & Interaksi sosial \\
\hline \multirow[t]{2}{*}{3} & \multirow[t]{2}{*}{ impulse buying } & $\begin{array}{l}\text { Pembelian dengan } \\
\text { spontan } \\
\text { Pembelian tanpa } \\
\text { berpikir akibat } \\
\text { Pembelian terburu-buru }\end{array}$ \\
\hline & & Pembelian emosional \\
\hline
\end{tabular}

\section{HASIL DAN PEMBAHASAN}

Pengaruh Product assortment dan Hedonic lifestyle dengan Impulse Buying

Dalam upaya mengetahui pengaruh antara product assortment dan hedonic lifestyle terhadap impulse buying, penulis menggunakan analisis korelasi berganda. Berdasarkan hasil perhitungan korelasi berganda, diperoleh nilai korelasi antara variabel product assortment dengan impulse buying sebesar 0,614 dengan korelasi antar variabel tersebut lebih besar dari 0,5 dan tingkat signifikansi $0,00<$ 0,05 . Karena nilai korelasi berada diantara $0,60-$ 0,799 maka hubungan antara product assortment dengan impulse buying dikatakan kuat. Sedangkan nilai korelasi antara variabel hedonic lifestyle dengan impulse buying sebesar 0,551 dengan korelasi antar variabel tersebut lebih besar dari 0,5 dan tingkat signifikansi $0,00<0,05$. Karena nilai korelasi berada diantara 0,40-0,599 maka hubungan antara hedonic lifestyle dengan impulse buying dikatakan sedang atau cukup kuat.

\section{Pengaruh Product assortment dan Hedonic lifestyle dengan Impulse Buying}

Untuk mengetahui pengaruh product assortment dan hedonic lifestyle dengan impulse buying secara parsial dan simultan maka dilakukan analisis sebagai berikut:

\section{Pengaruh Antar Variabel Secara Parsial}

Untuk mengetahui pengaruh product assortment dan hedonic lifestyle dengan impulse buying maka dilakukan analisis regresi dengan menggunakan alat statistik SPSS 17 dengan terlebih dahulu mentrasformasi data dari skala ordinal ditingkatkan menjadi skala interval. Hasil analisis pengaruh product assortment dan hedonic lifestyle terhadap impulse buying adalah sebagai berikut:
Table 2 Pengaruh product assortment terhadap impulse buying

\begin{tabular}{cccc}
\hline R & R Square & $\begin{array}{c}\text { Adjust R } \\
\text { Square }\end{array}$ & $\begin{array}{c}\text { Std Error of The } \\
\text { Estimate }\end{array}$ \\
\hline $0,669^{\mathrm{a}}$ & 0,447 & 0.444 & 3.285 \\
\hline
\end{tabular}

Sumber: Output SPSS diolah

$\mathrm{R}$ square dari hasil analisis dengan menggunakan SPSS yaitu sebesar $0,447 \times 100 \%=44,7 \%$. Variabel product assortment dalam penelitian ini mampu menjelaskan 44,7\% variasi yang terjadi dalam variabel impulse buying di Trans Studio Mall atau disebut dengan koefisien determinasi. Koefisien determinasi pada intinya mengukur seberapa jauh kemampuan sebuah model menerangkan variasi variabel independen.

Hasil analisis pengaruh hedonic lifestyle terhadap impulse buying adalah sebagai berikut:

Table 3 Pengaruh hedonic lifestyle terhadap impulse buying

\begin{tabular}{cccc}
\hline R & R Square & $\begin{array}{c}\text { Adjust R } \\
\text { Square }\end{array}$ & $\begin{array}{c}\text { Std Error of The } \\
\text { Estimate }\end{array}$ \\
\hline $0.523^{\mathrm{a}}$ & 0.274 & 0.270 & 3.765 \\
\hline
\end{tabular}

Sumber:Output SPSS Diolah

$\mathrm{R}$ square dari hasil analisis dengan menggunakan SPSS yaitu sebesar 0,274 x 100\%=27,4\% (koefisien determinasi). Variabel hedonic lifestyle dalam penelitian ini mampu menjelaskan $27,4 \%$ variasi yang terjadi dalam variabel impulse buying di Trans Studio Mall.

\section{Pengaruh Antar Variabel Secara Simultan}

Untuk mengetahui pengaruh product assortment dan hedonic lifestyle dengan impulse buying secara simultan, dilakukan analisis regresi dengan menggunakan alat statistik SPSS 17. Berdasarkan hasil perhitungan menggunakan SPSS diperoleh hasil sebagai berikut : Kedua variabel independen yaitu product assortment dan hedonic lifestyle dalam penelitian ini mampu menjelaskan $56,2 \%$ variasi yang terjadi dalam variabel dependen (impulse buying) di Trans Studio Mall Bandung. Sementara variasi lainnya $100 \%-56,2 \%=$ $44,8 \%$ dijelaskan oleh variabel lain yang tidak termasuk dalam penelitian ini. Selanjutnya untuk mengetahui variabel hedonic lifestyle dan product assortment mempunyai pengaruh secara signifikan terhadap variabel impulse buying maka dilakukan uji F. Tingkat signifikansi menggunakan alpha 0,05 .

Hasil uji $\mathrm{F}$ dilihat dalam tabel ANOVA dalam kolom sig, jika probabilitas kurang dari 0,05 maka dapat dikatakan terdapat pengaruh yang signifikan antara variabel independen dengan variabel dependen dan model regresi bisa dipakai untuk memprediksi variabel dependen. Hasil dari analisis SPSS menunjukan probabilitas sebesar 0,00 , karena $0,00<0,05$ maka terdapat pengaruh yang signifikan antara product assortment dan hedonic lifestyle dengan impulse buying dan model regresi bisa dipakai untuk memprediksi variabel impulse buying. Selanjutnya 
penulis akan membandingkan $\mathrm{F}$ hitung dengan $\mathrm{F}$ tabel dengan menggunakan degree of freedom (df), dengan hasil: Variabel product assortment dan hedonic lifestyle memiliki pengaruh terhadap impulse buying apabila $\mathrm{F}$ hitung $>\mathrm{F}$ tabel. Hasil analisis menggunakan SPSS menunjukan F hitung sebesar 126,299, karena $126,299>3,04$ maka variabel product assortment dan hedonic lifestyle memiliki pengaruh terhadap impulse buying, artinya semua variabel independen (hedonic lifestyle dan product assortment) secara bersamasama merupakan penjelas yang signifikan terhadap variabel dependen (impulse buying).

\section{SIMPULAN}

Hasil penelitian menunjukkan bahwa Product assortment yang ditawarkan Trans Studio Mall sudah dinilai baik. Konsumen terkesan dengan bangunan atau gedung Trans Studio Mall yang menarik dan megah. Konsumen juga menikmati ruangan di Trans Studio Mall yang terlihat rapi dan bersih, pengaturan cahaya dalam gerai sangat baik, musik yang diputar dalam outlet-outlet di Trans Studio Mall enak didengar, suhunya terasa nyaman dan display produk di Trans Studio Mall ditata dengan menarik. Menurut konsumen gang untuk berjalan dari satu tempat ke tempat yang lainnya memadai luasnya sehingga tidak berdesakan dan keragaman produk sangat baik. Product assortment di Trans Studio Mall diharapkan mampu mempengaruhi impulse buying konsumen, karena impulse buying itu dipengaruhi perasaaan nyaman berada di lingkungan pembelian yang diciptakan oleh Trans Studio Mall. Hal itu didukung oleh product assortment yang baik. Bangunan yang menarik dan megah membedakan Trans Studio Mall dengan mall lainnya yang ada di Bandung.

Hasil penelitian menunjukkan bahwa responden merasakan suasana Hedonic lifestyle di Trans Studio Mall. Konsumen menikmati acara berbelanja di Trans Studio Mall untuk menyenangkan dirinya ataupun orang lain. Konsumen juga pergi berbelanja dengan teman atau keluarganya untuk bersosialisasi. Trans Studio Mall perlu memperhatikan keinginan dan mengetahui cara menyenangkan konsumen. Hal itu diperlukan agar Manajemen Trans Studio Mall dapat menyusun strategi yang efektif untuk meningkatkan penjualan.

Pengaruh product assortment dan hedonic lifestyle yang dirasakan konsumen untuk mempengaruhi impulse buying di TSM. Berdasarkan hasil koefisien determinasi bahwa variabel independen product assortment dan hedonic lifestyle dalam penelitian ini mampu menjelaskan 56,2\% variasi yang terjadi dalam variabel dependen impulse buying di Trans Studio Mall Bandung.

\section{Saran}

1) Manajemen Trans Studio Mall hendaknya mempertahankan kinerja indikator-indikator Product assortment yang sudah dinilai baik oleh pelanggan Hasil hipotesis menunjukkan pengaruh antara Product assortment dengan impulse buying, maka dari itu manajemen Trans Studio Mall penting untuk mempertahankan indikatorindikator Product assortment.

2) Hipotesis menunjukkan adanya pengaruh antara hedonic lifestyle dengan impulse buying, maka sangat penting bagi Trans Studio Mall untuk memperhatikan keinginan dan kebutuhan konsumen Trans Studio Mall. Trans Studio Mall harus membuat strategi efektif untuk mendorong konsumen melakukan impulse buying dengan menyenangkan konsumen.

\section{DAFTAR PUSTAKA}

\section{Sumber Buku :}

Kotler, Philip, dan Keller . (2007).Manajemen Pemasaran Jilid I ed.12, PT. Indeks, Jakarta

Poespoprodjo, (1999). Logika Ilmu Menalar: DasarDasar Berpikir Tertib, Logis, Kritis, Analitis, Dialektis. Pustaka Grafika

Simamora, Henry, (2000), Manajemen Pemasaran Internasional, Surabaya:Pustaka Utama.

Utami, C. W. (2010). Manajemen Ritel: Strategi dan Implementasi Operasional Bisnis Ritel Moderen di Indonesia. Jakarta: Salemba Empat.

\section{Sumber Jurnal :}

Herabadi, et al. (2009). Consumption experience of impulse buying in Indonesia: Emotional aroousal and hedonistic considerations. Asian Journal of Social Psychology, 12, 20-31.

Park, E. J., Kim, E. Y., and Forney, J. C. (2006). A structural model of fashion- oriented impulse buying behavior, Journal of Fashion Marketing and Management, Vol. 10 No. 4, pp. 433-446.

Silvera, D. H., Lavack, A. M., and Kropp, F. (2008). Impulse buying: the role of affect, social influence, and subjective wellbeing, Journal of Consumer Marketing, Vol. 25, No. 1, pp. 23-33. 